\title{
Association between interleukin-1 receptor associated kinase 1 rs3027898 A/C gene polymorphism and rheumatoid arthritis
}

\author{
MAHDI ATABAKI $^{1}$, MOHAMMAD HASHEMI ${ }^{2}$, HAMID DANESHVAR $^{3}$ and EBRAHIM ALIJANI ${ }^{1}$ \\ ${ }^{1}$ Clinical Immunology Research Center, Zahedan University of Medical Sciences; ${ }^{2}$ Cellular and Molecular Research Center, \\ Zahedan University of Medical Sciences, Zahedan, Sistan and Baluchestan 98167-43181; \\ ${ }^{3}$ Department of Immunology, Kerman University of Medical Sciences, Kerman, Kerman 76169-14115, Iran
}

Received January 30, 2017; Accepted February 7, 2017

DOI: $10.3892 /$ br.2017.855

\begin{abstract}
Rheumatoid arthritis (RA) is a systemic autoimmune disease predominantly involving the synovial joints and affects up to $1 \%$ of adults worldwide. The aim of the present study was to determine whether the interleukin-1 receptor (IL1R)-associated kinase (IRAK1) rs3027898 gene polymorphism confers susceptibility to RA in a sample of patients from Iran. This gene encodes IRAK1, one of two putative serine/threonine kinases that associates with IL1R upon stimulation. IRAK1 is partially responsible for IL-1-induced upregulation of the transcription factor, nuclear factor $-\kappa \mathrm{B}$. The present case-control study was performed on 120 patients with RA and 120 healthy individuals. Genomic DNA was extracted from whole blood, and the gene polymorphism was evaluated using a tetra-primer amplification refractory mutation system-polymerase chain reaction method. The results demonstrated that there was no association between IRAK1 rs3027898 CA genotype and the risk of RA in women (odds ratio $=0.72,95 \%$ confidence interval $=0.41-1.49 ; \mathrm{P}=0.446$ ). Further studies with larger sample sizes and different ethnicities are required to validate the present findings.
\end{abstract}

\section{Introduction}

Rheumatoid arthritis (RA) is a chronic systemic disease of unknown etiology that affects the joints and causes kidney and other tissue damage. RA prevalence, according to multiple reports for different populations, is between 0.5 and $1 \%$ (1). $\mathrm{RA}$ is a global issue and occurs at any age; however, it is more common in women aged 40-50 years. Although the

Correspondence to: Mr. Mahdi Atabaki, Clinical Immunology Research Center, Zahedan University of Medical Sciences, Daneshgah Street, Zahedan, Sistan and Baluchestan 98167-43181, Iran

E-mail: atabaki80@gmail.com

Key words: rheumatoid arthritis, polymorphism, interleukin-1 receptor associated kinase 1 exact etiology of RA remains unknown, a series of immunological, genetic, infectious, environmental and hormonal factors contribute to it (2). It is thought that genetic factors may explain up to $60 \%$ of the susceptibility to RA. The human leukocyte antigen (HLA)-DR4 allele of the major histocompatibility complex (MHC) class II and other relevant alleles, are known to be genetic risk factors in RA patients (3). An important non-HLA gene that contributes to RA is the interleukin-1 receptor (IL1R)-associated kinase (IRAK1) gene. The $I R A K 1$ gene is located on chromosome $\mathrm{X}(\mathrm{Xq} 28)$ and is the first member of the IRAK family that binds to the intracellular domain of IL1R. IRAKI is subsequently phosphorylated and ubiquitinated, then binds to myeloid differentiation primary response gene 88 (MYD88) adaptor protein. This binding activates nuclear factor $(N F)-\kappa B$ so the signal is transferred into the nucleus and performs its function (4). Three $I R A K$-associated genes were subsequently discovered, including IRAK2, IRAKM and IRAK4. There are two domains in all IRAKs; a conserved N-terminal death domain and a central kinase domain. Subsequent to expression, these IRAKs are able to activate the NF- $\kappa \mathrm{B}$ signaling gene. Recent studies have demonstrated that activation of innate immune system, particularly $I R A K 1$, may elevate inflammatory protein production, such as C-reactive protein (CRP). Increased expression levels and activity of IRAKI induce signal transducer and activator of transcription 3 (STAT3) factor activation followed by transcription of the CRP gene, and CRP is an acute phase protein that is produced in RA (5). IRAKs are important mediators in toll-like receptor (TLR)/IL1R (TIR)-dependent signal transportation via MYD88 and partake in inflammatory responses. Among different IRAKs, IRAKI is important in the above-mentioned processes, and is essential in innate and adoptive immune system responses. Furthermore, MYD88 binds to interferon regulatory factors (IRFs) causing specific cytokine synthesis based on the type of TIR-inducing signal (6).

There are various SNPs in IRAK1 that affect its gene expression and functions. For example, recently, Chatzikyriakidou et al (7) reported statistically significant differences in the IRAK1 rs3027898 A>C polymorphism distribution between RA patients and control subjects $(\mathrm{P}=0.044)(7)$. Therefore, with respect to the role of the IRAKI gene in the pathogenesis of various autoimmune diseases, such as RA, it would be a suitable candidate for 
genetic studies. Therefore, the aim of the present study was to evaluate the possible association between the IRAKI $r s 3027898 \mathrm{~A} / \mathrm{C}$ variation and risk of RA in a sample of Iranian individuals.

\section{Materials and methods}

Subjects. The current case-control study was performed with 120 patients (16 males, 104 females) with RA with an average age of $44.6 \pm 12.9$ years, who met the American College of Rheumatology (ACR) criteria of RA (8). All participants were patients of the Rheumatology Clinic at Zahedan University of Medical Sciences (Zahedan, Iran) (9-11). The control group consisted of 120 healthy subjects (44 males, 76 females) with a mean age of $43.2 \pm 10.3$ years that were unrelated to the RA patients. The present study was approved by the ethics committee of Zahedan University of Medical Sciences, and informed consent was obtained from all patients and healthy individuals. Blood samples $(4 \mathrm{ml})$ were collected from each patient and healthy control into Na-EDTA tubes. The characteristics of the subjects participating in the current study are presented in Table I.

DNA extraction and polymerase chain reaction $(P C R)$ protocol. Genomic DNA was extracted from the peripheral blood samples that were collected, as described previously (9).

The IRAKI polymorphism was determined by tetraprimer amplification refractory mutation system (ARMS)-PCR. Two external primers (forward outer, 5'-CCATGCCTGGCTAATTTTTGTACTTTTT-3' and reverse outer, 5'-GTCTTCAGAAGCAAGTCAGGTTTCA TGT-3') and the two internal primers [forward inner (A allele), 5'-AGACCCTG GACGCTCAAGAATCA-3' and reverse inner (C allele), 5'-TGAGCTTTCCTGATGCCTTAC ACTTTAG-3'] were used. The primers were made by Bioneer Corp. (Daejeon, South Korea) The product sizes were 203 bp for the A allele, $157 \mathrm{bp}$ for the $\mathrm{C}$ allele and $314 \mathrm{bp}$ for the control band.

PCR was conducted using commercially available PCR premix (AccuPower PCR PreMix; Bioneer Corp.) according to the manufacturer's recommended protocol. Template DNA (1.5 $\mu \mathrm{l} ; \sim 100 \mathrm{ng} / \mu \mathrm{l}), 1 \mu \mathrm{l}$ each inner forward and reverse primer $(10 \mu \mathrm{M})$, and $1 \mu \mathrm{l}$ each outer forward and reverse primer $(12 \mu \mathrm{M})$ in $14.5 \mu \mathrm{l}$ DNase-free water were added into a 0.2-ml PCR tube containing the AccuPower PCR PreMix. The PCR cycling conditions for IRAKI were $95^{\circ} \mathrm{C}$ for $5 \mathrm{~min}$ followed by 30 cycles of $30 \mathrm{sec}$ at $95^{\circ} \mathrm{C}, 30 \mathrm{sec}$ at $66^{\circ} \mathrm{C}$, and $30 \mathrm{sec}$ at $72^{\circ} \mathrm{C}$, with a final step at $72^{\circ} \mathrm{C}$ for $10 \mathrm{~min}$ using a Bio-Rad thermal cycler (Bio-Rad Laboratories, Inc., Hercules, CA, USA). The PCR products were visualized using the Bio-Rad Gel Doc System (Bio-Rad Laboratories, Inc.) on $2 \%$ agarose gel containing $0.5 \mu \mathrm{g} / \mathrm{ml}$ ethidium bromide, and electrophoresis patterns were obtained (Fig. 1). The genotypes determined using this method were concordant with those determined by sequencing (Fig. 2). DNA sequencing is a technique used for determining the precise order of nucleotides within a DNA molecule. To ensure tetra-primer ARMS-PCR genotyping quality, the random samples were re-genotyped and no errors were identified in the genotyping results.
Table I. Demographic and biochemical characteristics of the study participants.

\begin{tabular}{lcc}
\hline $\begin{array}{l}\text { Individual } \\
\text { characteristics }\end{array}$ & $\begin{array}{c}\text { RA patients } \\
(\mathrm{n}=120)\end{array}$ & $\begin{array}{c}\text { Controls } \\
(\mathrm{n}=120)\end{array}$ \\
\hline Gender (female/male) & $104 / 16$ & $76 / 44$ \\
Age (years) & $44.6 \pm 12.9$ & $43.2 \pm 10.3$ \\
Disease duration (years) & $6.05 \pm 5.85$ & - \\
Rheumatoid factor positivity (\%) & 89.2 & - \\
Family history (\%) & 83.5 & - \\
CRP positivity (\%) & 91.7 & - \\
Anti-CCP positivity (\%) & 68.3 & - \\
\hline
\end{tabular}

CRP, C-reactive protein; CCP, cyclic citrullinated protein.

Statistical analysis. Statistical analysis was performed using commercial statistical software package, SPSS 18 software for windows (SPSS V18; SPSS Inc., Chicago, IL, USA). Possible associations between the IRAKI genotypes and RA were determined by computing the odds ratio (OR) and $95 \%$ confidence intervals (CIs) from logistic regression analyses. $\mathrm{P}<0.05$ was considered to indicate a statistically significant difference.

\section{Results}

The present study consists of 120 patients with RA and 120 healthy subjects. The genotypes and allele frequencies of the IRAK1 rs3027898 polymorphism are presented in Table II. No significant difference was identified between the women with regard to the IRAK1 rs3027898 polymorphism $(\mathrm{P}=0.446)$ and the $\mathrm{AC}$ genotype was not determined to be a risk factor for susceptibility to RA among women $(\mathrm{OR}=0.72$, 95\% $\mathrm{CI}=0.41-1.49 ; \mathrm{P}=0.446)$. In addition, the present study indicated that the rs3027898 A allele is not a risk factor for predisposing women to $\mathrm{RA}(\mathrm{OR}=0.83,95 \% \mathrm{CI}=0.54-1.26$; $\mathrm{P}=0.395)$. In men, no significant differences were identified between the RA patients and control subjects in the rs3027898 A allele indicating that this allele is not a risk factor for susceptibility to $\mathrm{RA}(\mathrm{OR}=1.02,95 \% \mathrm{CI}=0.32-3.25 ; \mathrm{P}=1.000)$.

\section{Discussion}

In the present study, the possible association of the IRAKI rs3027898 polymorphism and the risk of RA was examined in an Iranian population. To the best of our knowledge, it is the first study to date to focus on the influence of the IRAKI $r s 3027898 \mathrm{~A} / \mathrm{C}$ polymorphisms in the susceptibility of an Iranian population to RA. No positive association was identified between this polymorphism and susceptibility to RA in the study population.

RA is a complex disease that affects $\sim 0.5 \%$ of the adult population worldwide, and occurs in 20-50 cases per 100,000 annually, predominantly in women aged $>40$ years (12). The onset of the RA has important diagnostic, prognostic and therapeutic significance, and is yet to be defined. The prevalence of RA, in terms of occurrence and clinical symptoms, has unknown geographical borders, that may result in diverse 
Table II. Distribution of genotypes and allelic frequencies of IRAKI rs3027898 polymorphisms between RA (case; $\mathrm{n}=120$ ) and healthy subjects (control; $\mathrm{n}=120$ ).

\begin{tabular}{lcccc}
\hline IRAK1 rs3027898 & RA & Control & OR $(95 \%$ CI $)$ & P-value \\
\hline Women & & & & - \\
CC & $30(28.8)$ & $17(22.4)$ & Reference & 0.446 \\
CA & $51(49.0)$ & $40(52.6)$ & $0.72(0.41-1.49)$ & 0.397 \\
AA & $23(22.1)$ & $19(25.0)$ & $0.69(0.29-1.61)$ & - \\
Allele & & & Reference \\
C & $111(53.3)$ & $74(48.7)$ & $0.83(0.54-1.26)$ & 0.395 \\
A & $97(46.7)$ & $78(51.3)$ & & - \\
Men & & & Reference & 1.00 \\
C & $9(56.3)$ & $25(56.8)$ & $1.02(0.32-3.25)$ & \\
A & $7(43.7)$ & $19(43.2)$ & \\
\hline
\end{tabular}

Data adjusted for gender and age. LGALS3, lectin, galactoside-binding, soluble, 3; OR, odds ratio; CI, confidence interval.

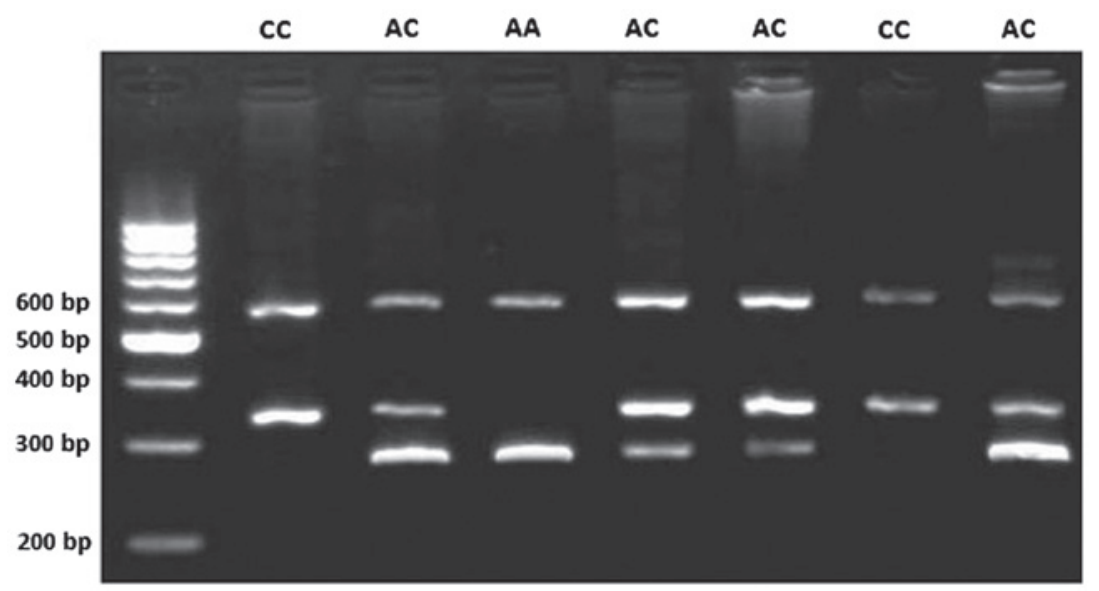

Figure 1. Electrophoresis pattern of tetra amplification refractory mutation system-polymerase chain reaction for detection of IRAK1 polymorphism. IRAK1, interleukin-1 receptor associated kinase 1.

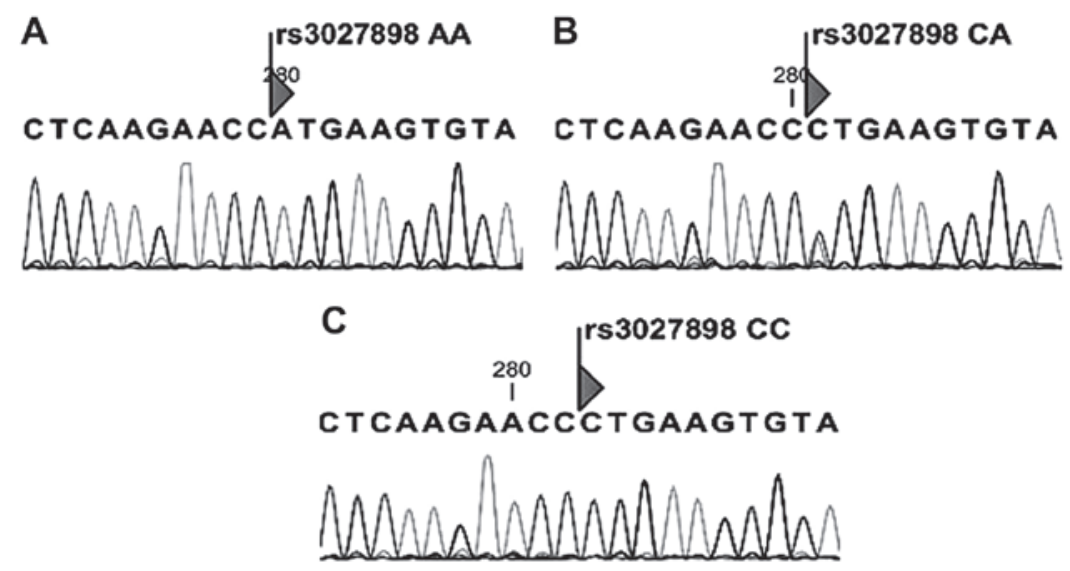

Figure 2. Sequencing results of interleukin-1 receptor-associated kinase genomic DNA. (A) homozygous rs3027898 AA, (B) heterozygous rs3027898 CA and (C) homozygous rs3027898 CC genotypes.

genetic structures, ecological factors and socio-demographic elements (12). There are numerous genes that have been associated with the predisposition to RA (12).
IRAK1 is activated by IRAK4/MYD88 in response to TIR signaling (13). This intracellular kinase has been reported to have positive effects on immune response due to the 
activation of NF- $\mathrm{KB}$ and mitogen-activated protein kinase and the tumor necrosis factor receptor superfamily. These genes and transcription factors serve an important function in the inflammation process of RA and recall immune cells to the synovial membrane of the affected joints (14).

In the present study, no association was identified between the IRAK1 rs3027898 AA genotype and the risk of RA in women $(\mathrm{OR}=0.69,95 \% \mathrm{CI}=0.29-1.61 ; \mathrm{P}=0.397)$. There was no significant difference between the women in the groups (RA patients and control subjects) regarding the IRAKI rs3027898 polymorphism $(\mathrm{P}=0.446)$, which suggests that the $\mathrm{AC}$ genotype was not a risk factor for susceptibility to $\mathrm{RA}$ among women $(\mathrm{OR}=0.72,95 \% \mathrm{CI}=0.41-1.49 ; \mathrm{P}=0.446)$. Furthermore, the present study found that the rs3027898 A allele was not a risk factor for predisposing women to RA in the current population $(\mathrm{OR}=0.83,95 \% \mathrm{CI}=0.54-1.26$; $\mathrm{P}=0.395)$. In men, no significant differences were identified between the rs3027898 A allele and RA, demonstrating that this allele is not a risk factor for susceptibility to $\mathrm{RA}(\mathrm{OR}=1.02$, 95\% CI=0.32-3.25; $\mathrm{P}=1.000$ ).

In contrast to the present data, Zhang et al (15) evaluated IRAK1 rs3027898 C/A gene polymorphisms in a Chinese population and found that the AA genotype was associated with a significantly increased risk of RA $(\mathrm{OR}=1.91$, 95\% CI=1.12-3.26; $\mathrm{P}=0.017)$. In addition, analysis of IRAKI polymorphisms and RA with Song et al (16) revealed an association between inflammatory arthritis and the rs3027898 CC genotype $(\mathrm{OR}=2.602,95 \% \mathrm{CI}=1.387-4.879 ; \mathrm{P}=0.003)$.

The findings of the present study differ from those of Yang et al (17) in 2016. Their case-control study, in a sample of RA patients in China, showed that the IRAKI rs3027898 $\mathrm{C}$ allele was associated with an increased risk of RA with an odds ratio $(\mathrm{OR})=1.4$ and 95\% CIs=1.093-1.793 $(\mathrm{P}=0.008)$.

Chatzikyriakidou et al (7) performed a study in Greece on 136 RA patients and 147 control subjects, and reported a strong statistically significant difference in the IRAK1 rs 3027898 $\mathrm{A}>\mathrm{C}$ polymorphism distribution between RA patients and control subjects $(\mathrm{P}=0.044)(7)$, which was not consistent with the present study.

In conclusion, due to contradictory results from different studies on the same polymorphism, further studies in other ethnic groups and with larger sample sizes are required, and may facilitate the understanding of whether this polymorphism is associated with susceptibility to RA.

\section{Acknowledgements}

The authors would like to thank all subjects for participating in the current study.

\section{References}

1. Silman AJ and Pearson JE: Epidemiology and genetics of rheumatoid arthritis. Arthritis Res 4 (Suppl 3): S265-S272, 2002.

2. Bowes $\mathrm{J}$ and Barton A: Recent advances in the genetics of RA susceptibility. Rheumatology (Oxford) 47: 399-402, 2008.

3. Perricone C, Ceccarelli F and Valesini G: An overview on the genetic of rheumatoid arthritis: A never-ending story. Autoimmun Rev 10: 599-608, 2011.

4. Huang YS, Misior A and Li LW: Novel role and regulation of the interleukin-1 receptor associated kinase (IRAK) family proteins. Cell Mol Immunol 2: 36-39, 2005.

5. LakoskiSG,LiL,Langefeld CD,Liu Y,HowardTD,Brosnihan KB, $\mathrm{Xu}$ J, Bowden DW and Herrington DM: The association between innate immunity gene (IRAK 1 ) and C-reactive protein in the Diabetes Heart Study. Exp Mol Pathol 82: 280-283, 2007.

6. Chiang EY, Yu X and Grogan JL: Immune complex-mediated cell activation from systemic lupus erythematosus and rheumatoid arthritis patients elaborate different requirements for IRAK1/4 kinase activity across human cell types. J Immunol 186: 1279-1288, 2011.

7. Chatzikyriakidou A, Voulgari PV, Georgiou I and Drosos AA: A polymorphism in the 3'-UTR of interleukin-1 receptor-associated kinase (IRAK1), a target gene of miR-146a, is associated with rheumatoid arthritis susceptibility. Joint Bone Spine 77: 411-413, 2010.

8. Arnett FC, Edworthy SM, Bloch DA, McShane DJ, Fries JF, Cooper NS, Healey LA, Kaplan SR, Liang MH, Luthra HS, et al: The American Rheumatism Association 1987 revised criteria for the classification of rheumatoid arthritis. Arthritis Rheum 31: 315-324, 1988.

9. Hashemi M, Moazeni-Roodi AK, Fazaeli A, Sandoughi M, Bardestani GR, Kordi-Tamandani DM and Ghavami S: Lack of association between paraoxonase-1 Q192R polymorphism and rheumatoid arthritis in southeast Iran. Genet Mol Res 9: 333-339, 2010.

10. Hashemi M, Moazeni-Roodi AK, Fazaeli A, Sandoughi M, Taheri M, Bardestani GR, Zakeri Z, Kordi-Tamandani DM and Ghavami S: The L55M polymorphism of paraoxonase-1 is a risk factor for rheumatoid arthritis. Genet Mol Res 9: 1735-1741, 2010.

11. Sandoughi M, Fazaeli A, Bardestani G and Hashemi M: Frequency of HLA-DRB1 alleles in rheumatoid arthritis patients in Zahedan, southeast Iran. Ann Saudi Med 31: 171-173, 2011.

12. Carmona L, Cross M, Williams B, Lassere M and March L: Rheumatoid arthritis. Best Pract Res Clin Rheumatol 24: 733-745, 2010.

13. No authors listed: Correction for Yang et al., Interleukin 1 receptor-associated kinase 1 (IRAK1) mutation is a common, essential driver for Kaposi sarcoma herpesvirus lymphoma. Proc Natl Acad Sci USA 112: E2412, 2015.

14. Guo L, Chen CH, Zhang LL, Cao XJ, Ma QL, Deng P, Zhu G, Gao CY, Li BH, Pi Y, et al: IRAK1 mediates TLR4-induced ABCA1 downregulation and lipid accumulation in VSMCs. Cell Death Dis 6: e1949, 2015.

15. Zhang $\mathrm{H}, \mathrm{Pu}$ J, Wang X, Shen L, Zhao G, Zhuang C and Liu R: IRAK1 rs3027898 C/A polymorphism is associated with risk of rheumatoid arthritis. Rheumatol Int 33: 369-375, 2013.

16. Song GG, Bae SC, Seo YH, Kim JH, Choi SJ, Ji JD and Lee YH: The association between susceptibility to inflammatory arthritis and miR-146a, miR-499 and IRAK1 polymorphisms. A meta-analysis. Z Rheumatol 74: 637-645, 2015.

17. Yang XK, Li P, Zhang C, Leng RX, Li S, Liu J, Li BZ, Pan HF and Ye DQ: Association between IRAK1 rs3027898 and miRNA-499 rs3746444 polymorphisms and rheumatoid arthritis: A case control study and meta-analysis. Z Rheumatol: Aug 31, 2016 (Epub ahead of print). 